\title{
Income Distribution and Inequality
}

\author{
Frank A. Cowell
}

STICERD,

London School of Economics

DARP 94

October 2007

\author{
The Toyota Centre \\ Suntory and Toyota International \\ Centres for Economics and Related \\ Disciplines \\ London School of Economics \\ Houghton Street \\ London WC2A 2A
}

(+44 020) 79556674

* author contact: f.cowell@lse.ac.uk 


\begin{abstract}
What are the principal issues on which research on income distribution and inequality focus? How might that focus shift in the immediate future? Prepared for the The Elgar Handbook of Socio-Economics.
\end{abstract}

JEL Classification: C13, D63 


\section{Distributional Analysis Research Programme}

The Distributional Analysis Research Programme was established in 1993 with funding from the Economic and Social Research Council. It is located within the Suntory and Toyota International Centres for Economics and Related Disciplines (STICERD) at the London School of Economics and Political Science. The programme is directed by Frank Cowell. The Discussion Paper series is available free of charge. To subscribe to the DARP paper series, or for further information on the work of the Programme, please contact our Research Secretary, Leila Alberici on:

Telephone: UK+20 79556674

Fax: $\quad$ UK+20 79556951

Email:_l.alberici@lse.ac.uk

Web site: $\quad$ http://sticerd.Ise.ac.uk/DARP

(C) Author: Frank Cowell. All rights reserved. Short sections of text, not to exceed two paragraphs, may be quoted without explicit permission provided that full credit, including $\odot$ notice, is given to the source. 
The produce of the earth - all that is derived from its surface by the united application of labour, machinery, and capital, is divided among three classes of the community; namely, the proprietor of the land, the owner of the stock or capital necessary for its cultivation, and the labourers by whose industry it is cultivated. [...] To determine the laws which regulate this distribution, is the principal problem in Political Economy. - David Ricardo, On The Principles of Political Economy and Taxation. London: John Murray, 1817 (third edition 1821)

\section{Introduction}

The central place that Ricardo accorded the subject of income distribution in 19th century Political Economy is appropriate also in 21st century SocioEconomics. Although the field was relatively neglected by economists for several decades, in the last fifteen years there has been a resurgence of interest driven partly by developments in economic theory and partly by major developments in the interpersonal income distributions within many developed countries (Atkinson 1997).

In recent years the subject of economic inequality has developed in such a way as to have a life of its own separate from the obvious connection with the distribution of income, the distribution of wealth, the structure of wages and other related empirical topics. This distinct area of study has been built upon new insights in welfare economics and on the relationship to information theory (Cowell 2000, Sen and Foster 1997).

Our treatment of this pair of subjects is organised as follows. Section 3 examines the ways in which economic analysis has attempted to explain what drives income distribution; in section 4 we will look at ways of analysing the personal income distribution as a prelude to a more thorough consideration of inequality (section 5); section 6 looks at new directions in which the analysis may proceed. But first let us briefly think about the main focus of our subject.

\section{Income}

Why the focus on income rather than some other measurable quantity? In many treatments of the subject income plays one of two roles, sometimes both:

- Income as a proxy for economic welfare. If one adopts an individualistic, welfarist approach to social economics then it is reasonable to be concerned with individual well-being or utility. In some respects the flow of income captures this, but it has been argued that consumption expenditure may be a more appropriate economic indicator (Blundell and Preston 1998). ${ }^{1}$ It

\footnotetext{
${ }^{1}$ Among other things use of consumption data can avoid a number of difficult technical problems that arise from the presence in practice of zero and negative incomes.
} 
should also be acknowledged that individual well-being may be determined not only by the level of one's own income but also by its relation to the incomes of others (Ferrer-i-Carbonell 2005).

- Income as command over resources. This role of income can be interpreted in more than one way. If one has in mind spending power then perhaps disposable income (income after taxes and compulsory deductions?) may be an appropriate concept. But if "inequality" is associated with economic power and status then a measure of wealth may be more appropriate.

The focus on income as conventionally defined clearly has shortcomings. An uncritical use of income in either of the above roles may neglect questions of time (people's incomes often change systematically over their lifetime) and of risk (people's incomes often change erratically in the short run): more sophisticated income concepts can be used that take account of these factors, but it is harder to get reliable data to estimate them. Also left open are important theoretical and practical questions: for each type of income one needs to be clear about who or what the "income receiver" is (a single person? a family or household? a firm? a taxpayer?); particular care must be taken when using standard data sources to make international comparisons (Atkinson and Brandolini 2001).

\section{Economics and income distribution}

In economic analysis "income distribution" is interpreted in two principal ways: the functional distribution of income - i.e. the distribution of income among factors - and the size distribution of income (or distribution of income among persons).

We briefly deal with the way each of these is conventionally handled in economics, focusing on the forces that determine the shape of the income distribution (section 3.1). Then, in section 3.2 we will look at challenges to the orthodoxy and the way these challenges have enhanced our understanding about the analysis of income distribution in recent years.

\subsection{The standard approach}

Functional distribution. The functional distribution of income is an integral part of the economic analysis of relative prices, output and employment. In this sense there are several theories of income distribution corresponding to different theoretical and ideological stances on these central issues. However, these various analyses usually focus on the same basic economic concepts: employment of the factors of production - land, labour and capital - and the rates of remuneration of their services - rent, wages and profit.

The conventional approach is to treat questions of distribution as part of the neoclassical analysis of prices and resource allocation in a story such as the following. A competitive firm takes the price it can get for its output and the prices it must pay for inputs as given in the market: it selects its level of 
output and adjusts its demand for inputs so as to maximise profits at those prices; each household takes as given the prices paid to it for the labour services supplied by members of the household just as takes as given the prices to be paid for goods and services it needs, and: it adjusts the quantities of the goods and services demanded or supplied in the market so as to maximise satisfaction within the limitations imposed by its budget. In this story prices adjust so as to ensure equilibrium in all markets: equilibrium means that aggregate supply of each commodity is at least as great as aggregate demand. In particular factor incomes, the reward for each type of labour, each natural resource and capital asset is determined by its market clearing price. So the functional distribution of income - the issue referred to directly by Ricardo in the epigraph - is in this way automatically determined by the market mechanism. Shocks to the system - for example changes in the stock of natural resources alters, or a shift in the preference patterns of consumers - will change the income distribution through this mechanism as prices adjust to new equilibrium levels.

Personal distribution. The distribution of income between persons or between households can be fitted into the above scenario. Key decisions that determine incomes in the long run can each be analysed as particular cases of the household's optimization problem: household saving, self-investment in human capital or the purchase of education for children are determined by price signals. To complete the theory of income distribution within this framework one also needs a description of the system of property rights that prevails within the community. The question of who owns the natural resources, the capital equipment and the profits of the firms is central to the determination of household incomes: household budgets are jointly determined by market prices and property rights and will be affected by a change in the pattern of ownership, or in the system of ownership.

However, more is required to complete the personal income distribution story. In order to draw conclusions about the distribution of income in the long-run one also needs to consider the evolution of property rights across the generations.(Piketty 2000). This will depend, among other things, on how families are formed (do the rich predominantly marry the rich? ${ }^{2}$ do the poor have more children?) on the motives for bequeathing wealth to the next generation (do parents compensate disadvantaged children? is the amount bequeathed the outcome of dynastic optimisation or largely a matter of chance ${ }^{3}$ ) and the role of the State through taxation (Cremer and Pestieau 2006).

\subsection{Challenges and developments}

The orthodox neoclassical story outlined in section 3.1 has been called into question on account of its restrictive assumptions concerning the economic processes involved. Because these assumptions are central to the theory rather than be-

\footnotetext{
${ }^{2}$ See for example Fernández et al. (2005), Liu and Lu (2006).

${ }^{3}$ See for example Arrondel and Laferrère (2001), Kopczuk and Lupton (2007).
} 
ing merely convenient simplifications, many economists have questioned the relevance of various aspects of the standard account of income distribution. We may briefly mention three points of focus.

The role of prices. The predominant interest of neoclassical orthodox theory of income distribution in smooth adjustments to market clearing equilibria may be inappropriate to a theory of the functional distribution of income. As a response to this, economists who are strongly influenced by Keynes's approach to macroeconomics have developed a number of alternative theories of the functional distribution of income using components of the Keynesian system, for example the work of Kaldor (1955) and Pasinetti (1962). Key features of such alternative theories are rule-of-thumb savings decisions by capitalists and workers and a rigid technique by which labour and capital are combined to produce output; they play a role in some of the modern theory of growth and its relationship to factor incomes (Bertola 1993).

Monopoly power. The standard theory neglects barriers to competition and the monopoly power as of secondary importance in the competitive market story. Restraints on competition - in the form of segmentation of the labour market and outright discrimination - are of major importance in analysing the lower tail of the size distribution of earnings; and monopoly power may be particularly important in the upper tail, for example, in the determination of earnings in professions with restricted entry. Monopolistic pricing by firms has also been seen as of prime importance in the functional distribution of income (Kalecki 1939): such power plays an important part in the Marxian concept of exploitation and in distribution theories based on struggle between classes representing different factors of production. The assumption of competition is also likely to be inadequate in analysing economics that have a substantial public sector.

Modern treatments of the labour market take seriously the problem of monopsony by powerful firms in determining labour incomes and the potential role for a minimum wage (Manning 2003).

Information. The standard story in section 3.1 assumes effectively perfect information on the part of economic agents. However, uncertainty is itself a potent force generating inequality in both labour income and income from assets, in that the rich not only are better able to bear risk but also may have superior information which can be exploited in the stock market and the labour market. Moreover, some of the barriers to competition may have been erected by firms in response to uncertainty. Hence considerable interest has developed in the distributional implications of theories of output, employment and the structure of wages that explicitly incorporate imperfect information, in particular screening and signalling, phenomena that may result in equilibrium income inequality (Salanié 1997). Because of imperfect information it is in the interest of economic 


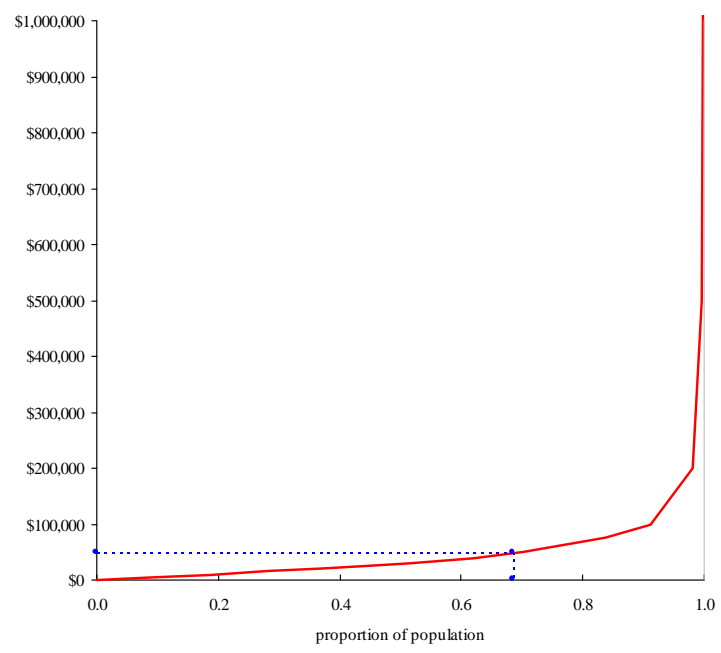

Figure 1: Parade diagram, US income before tax 2003

agents to make use of social networks formed from social contacts which may also buttress equilibrium (Ioannides and Loury 2004, Manski 2000).

\section{The personal distribution}

\subsection{Representations of income distribution}

Let us first examine the problems of depicting and interpreting the personal income distribution; then we will briefly consider the merits of formal modelling.

Statistical tools. To present the bald facts about income inequality one could just draw an empirical frequency distribution (histogram). But it is worth considering two other presentations of the data that have become familiar in the literature; we will illustrate the techniques using readily available tax data from the United States.

The background story for the first presentation is eloquently set out in Pen (1974). ${ }^{4}$ Imagine that each person's height were in proportion to his income and that the entire population were to file past in a parade that lasted exactly one hour. If we do this thought experiment for the US then the picture that emerges is that shown in Figure $1 .^{5}$ It is clear that this is just the inverse of the

\footnotetext{
${ }^{4}$ Pen's story was originally told for the UK and for income distribution data from the $1960 \mathrm{~s}$. Nevertheless the central message is still valid for the 21 st century and for other countries' data.

${ }^{5}$ Source: http://www.irs.gov/taxstats/indtaxstats/article/0,id=134951,00.html. Table 1.1-2003, Individual Income Tax Returns, Selected Income and Tax Items, by Size and Ac-
} 
conventional distribution function $F$ : if $x$ is income then $p=F(x)$ gives the proportion of the population with incomes less than or equal to $x$ and Figure 1 just plots $x$ against $p$. One standard feature of empirical income distributions emerges clearly from the diagram: the dotted line depicts the position of the person with average income $(\$ 48,889)$ and it is clear that this is more than twothirds along in the parade (so that the mean is substantially greater than the median).

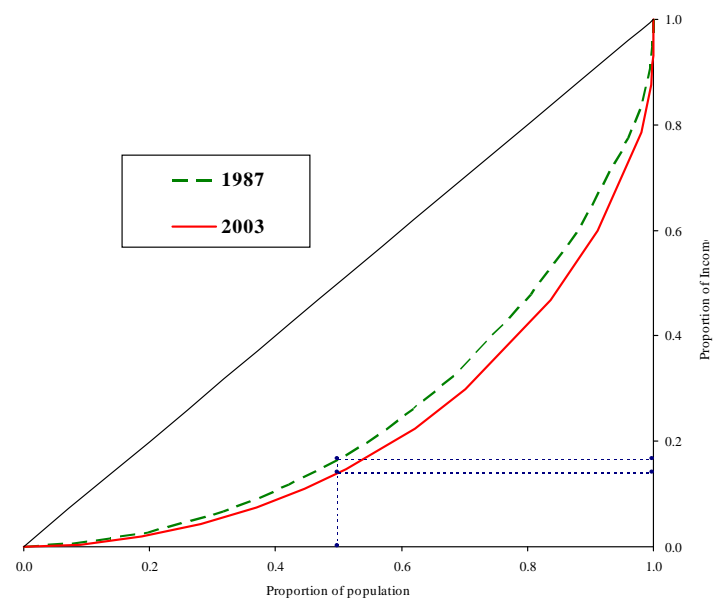

Figure 2: Lorenz Diagram, US income before tax 1987 and 2003

The second standard presentation is shown (using the same data source) in Figure 2. The horizontal axis is just as for Figure 1: on the vertical axis is plotted $s$, the income shares of the population. The Lorenz curve (Lorenz 1905) is a graph of income shares against population shares for a particular distribution so that a particular $(p, s)$ point can be read as "the bottom $100 p \%$ of the population receive $100 s \%$ of total income." ${ }^{6}$ It is clear that this graph captures an intuitive concept of inequality comparison: to see this Figure 2 also includes the corresponding graph for 1987; note that the share of the bottom $50 \%$ of the population $(p=0.5)$ in 2003 is unambiguously less than in 1987 and that the same conclusion would have been obtained if we had chosen any other $p$ -

cumulated Size of Adjusted Gross Income. These data do not embody the ideal definition of income and income-receiver for welfare analysis (below) but they can be conveniently used to illustrate all the techniques presented here. The data have been truncated below to eliminate negative and zero incomes to provide a consistent distribution that can be used in all the presentation techniques covered below - Pen (1974) did not truncate his data, but used only the parade presentation.

${ }^{6}$ Two points to note. (1) Because the population is implicitly arranged in ascending order of income the graph must be increasing and convex and start from $(0,0)$. (2) If there were perfect equality then everywhere we would have $p=s$ and the Lorenz curve would be a straight line; following convention this has been drawn in Figure 2. 
value; so according to this "shares ranking" income seems to be more unequally distributed in 2003 than in 1987. One might wonder whether the intuition could or should be formalised: this point is taken up in section 5 below.

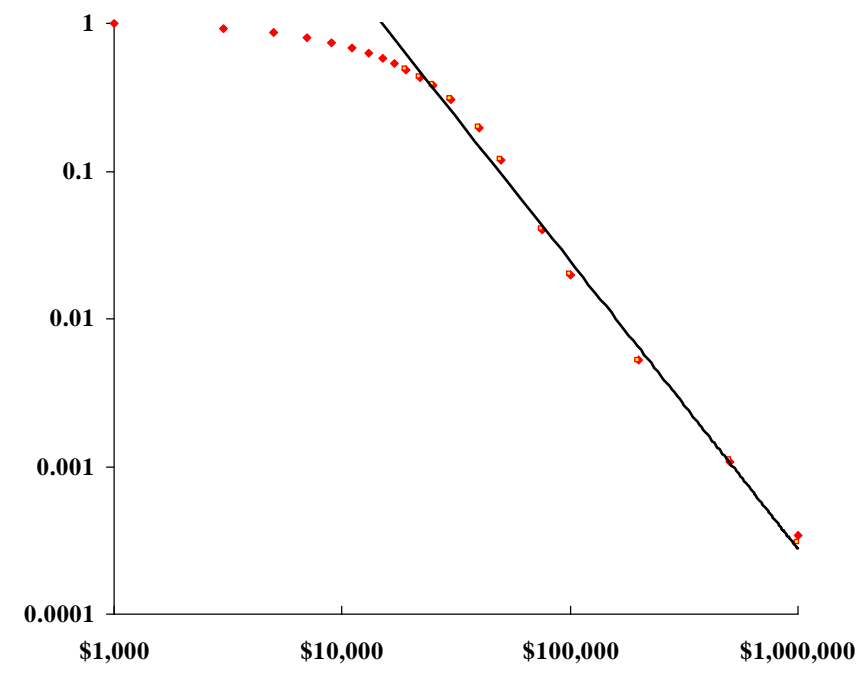

Figure 3: Pareto Diagram: US Pretax Income $2003(\alpha=1.95)$

Modelling the distribution. Once one considers anything beyond the simplest example of interpersonal income distribution there is a strong temptation to find some way of simplifying the representation of the distribution and its associated inequality. One way of doing this is to use a parametric model - in other words a suitable functional form, where "suitability" is interpreted as meaning that the salient features of the empirical distribution are captured. There are several candidate functional forms borrowed from statistics including the lognormal, beta and gamma distributions (Cowell 2007, Kleiber and Kotz 2003), but of particular interest is Pareto (1965)'s insight, all the more remarkable since it was based on the limited data available at the end of the 19th century. Figure 3 presents the same information as that presented in Figure 1 but now it plots $1-F(x)$ against income $x$, each on a logarithmic scale. A naked-eye inspection suggests that the points where $x$ is at least $\$ 50,000$ lie almost on a straight line, as shown. ${ }^{7}$ If one accepts the straight-line representation on this diagram for $x \geq x_{0}$ where $x_{0}:=\$ 50,000$ then in this income range we have

$$
F(x)=1-\left[\frac{x}{x_{0}}\right]^{\alpha}
$$

\footnotetext{
${ }^{7}$ For demonstration purposes this has been fitted using OLS to the top 11 observations.
} 
where the parameter $\alpha$ is the slope of the fitted line in Figure 3 .

Clearly the advantage of this is that the complexity of the distribution is reduced to a single parameter $\alpha$ - the lower is the value of this parameter, the "fatter" is the tail of the associated frequency distribution and, in some sense, the higher is the inequality displayed by the distribution. Some of the disadvantages are obvious: no attempt is made to capture information from the bottom end of the income distribution, the estimate of $\alpha$ may be quite sensitive to the statistical method employed (Cowell and Victoria-Feser 2007) and the use of $\alpha$ as an indicator "equality" is based on nothing stronger than an informal impressionistic argument.

From the time of Pareto's discovery of this relationship (1896) there has been interest in whether it somehow characterises a "law" of income distribution whether the straight-line approximation described above is generally a good one (it is) and whether it is reasonable to assume that across countries there is a natural tendency for $\alpha$ to approach one particular value (it isn't) (Persky 1992).

\subsection{Income distribution: recent developments}

A renewed interest in income distribution has developed because of recent history of the personal income distribution. After several decades of apparent stasis from the late 1970s onwards there has been a remarkable increase in the dispersion of incomes in many countries. Figure 4 (taken from Piketty and Saez 2003) demonstrates one aspect of the situation for the case of the USA: ${ }^{8}$ this charts the shares of the topmost income receivers over the 20th century.

The apparent secular increase in inequality is in both income derived from assets (note the role played by capital gains in this) and in labour income. This latter component has been driven by a recent increased dispersion of wage rates in industrialised countries (Gottschalk and Smeeding 1997, 2000); explanations for this remarkable phenomenon have been sought in the effects of technological advances on wage dispersion via productivity growth(Acemoglu 2002, Blau and Kahn 1996, Goldin and Katz 1996, Krueger 1993, DiNardo and Pischke 1997) and in the effects of international trade (Burtless 1995, Krugman and Venables 1995, Marjit and Acharyya 2003, Richardson 1995),

\section{Inequality}

To pass from the description and analysis of income distribution to a systematic consideration of inequality one needs to address a number of questions about the value judgments implicit in inequality comparisons and a number of ethical and practical questions associated with the use of an inequality measure.

\footnotetext{
${ }^{8}$ The increase in inequality shown by the shares ranking (Figure 2) is consistent with this: in contrast to Figure 2 which plots the income share $s$ of the bottom $p$ of the population, Figure 4 plots $1-s$ (corresponding to the top $1-p$ of the population) against time.
} 


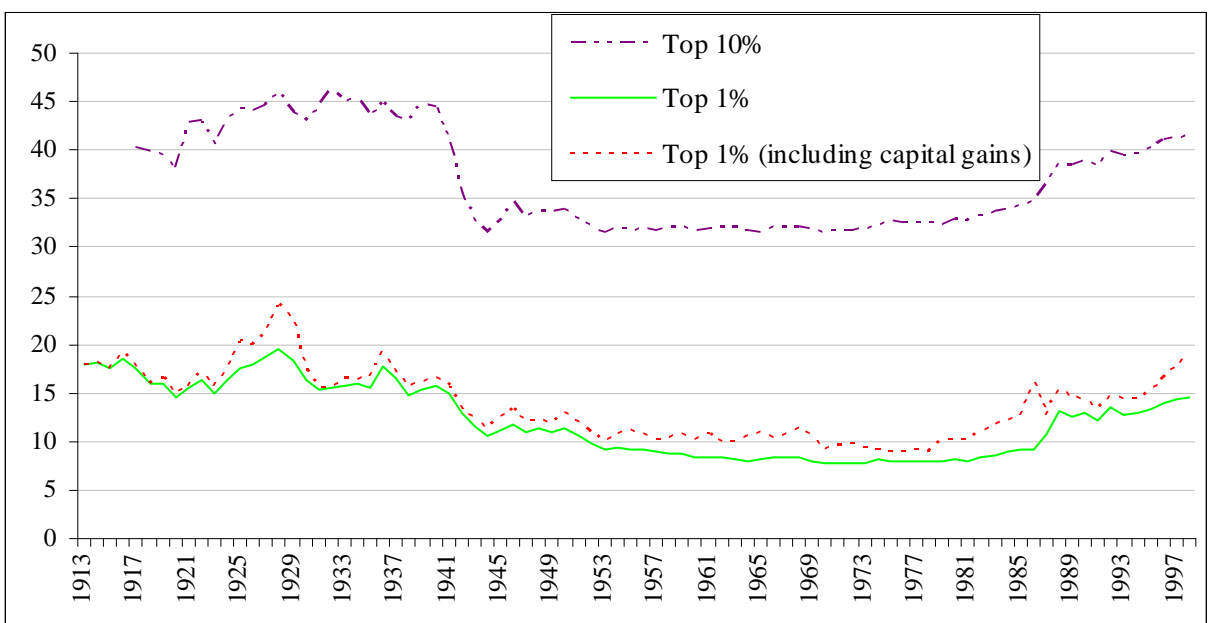

Figure 4: Top income shares in the United States

\subsection{Connections with income distribution}

Values. Perhaps the overriding question is, why one should be concerned with inequality? The standard answer is that it is rooted in an ethical approach to distributional questions (Sen and Foster 1997). Further, social values are in turn related to individual concerns and views: people care about distributional fairness and they reveal a concern for fairness through their behaviour in experimental settings (Charness and Rabin 2002, Fehr and Fischbacher 2002, 2003); to some extent a concern for fairness is also revealed in surveys (Inglehart et al. 2004)

A fundamental concept that is usually applied in inequality comparisons captures an element of this fairness-in-distribution point. The transfer principle (Dalton 1920) states the following: take an $n$-person income distribution $\left(x_{1}, x_{2}, \ldots, x_{n}\right)$ where $x_{i}$ is the income of person $i$; for any $i$ and $j$ among these $n$ persons consider the distribution formed by transferring a small amount of income $\delta$ from $i$ to $j$ (so $x_{i}$ is replaced by $x_{i}-\delta$ and $x_{j}$ is replaced by $x_{j}+\delta$ ); then, if $x_{i}<x_{j}$ the income distribution must become more unequal, if $x_{i}>x_{j}$ the income distribution must become less unequal. We have seen a glimpse of this principle in the representation of the income distribution using the Lorenz curve (Figure 2): one can imagine the 2003 distribution being "created" from the 1987 distribution by a series of poorer-to-richer transfers that successively reduce the income shares of the poorer members of the community; this implies that the 2003 distribution (outer Lorenz curve) must exhibit greater inequality than the 1987 distribution (inner Lorenz curve) (Atkinson 1970). 
Measurement. Why should one be interested in inequality measurement? One good answer is that the "shares ranking" outlined in section 4.1 is limited as a practical tool: the type of clear-cut conclusion drawn from Figure 2 ("2003 is more unequal than 1987") is not always possible because in many instances the relevant Lorenz curves intersect; to resolve the apparent ambiguity in the Lorenz comparison a summary numerical value for each Lorenz curve is sought. An appealing intuitive way of doing this is to take the area trapped between the Lorenz curve and the equality line in Figure 2: the normalised value of this area $^{9}$ yields the Gini coefficient. Formally the Gini is defined as

$$
\frac{1}{2 n^{2} \bar{x}} \sum_{i=1}^{n} \sum_{j=1}^{n}\left|x_{i}-x_{j}\right|
$$

where $\bar{x}:=\frac{1}{n} \sum_{i=1}^{n} x_{i}$ denotes mean income. The formula (1) provides another simple and natural interpretation: take all the possible pairs of income-receivers in society $(i, j)$ and compute the absolute difference between their incomes - the Gini is a normalised average of those differences.

In view of this attractive solution to the measurement problem, the question arises, why not just use the Gini coefficient to quantify inequality and leave the matter there? There are two main points in reply. First, there are other perfectly good summary statistics that combine intuitive appeal with familiarity and simplicity of computation; for example, one could use the coefficient of variation

$$
\sqrt{\frac{1}{n} \sum_{i=1}^{n}\left[\frac{x_{i}}{\bar{x}}-1\right]^{2}}
$$

which is obviously related to the variance; this and other intuitively reasonable measures may deserve to be considered alongside the Gini coefficient. ${ }^{10}$ Second, it may be more appropriate to base inequality measurement on some sort of social evaluation of income distribution rather than just on personal intuition.

\subsection{Welfare economics and distribution}

In the context of income-distribution analysis social welfare can be represented as a value $W\left(x_{1}, x_{2}, \ldots, x_{n}\right)$ where $W$ is a function with "suitable" properties. It is commonly, though not universally, assumed that social-welfare function $W$ can be written in additive form so that the social welfare associated with a particular income distribution is given by

$$
\sum_{i=1}^{n} u\left(x_{i}\right)
$$

\footnotetext{
${ }^{9}$ Normalisation involves dividing this area by the area of the whole triangle, namely $\frac{1}{2}$. This is exactly the same as the formula given in 1.

${ }^{10}$ Because different inequality measures encode different information about the income distribution, thay can give qualitatively different answers in cases where Lorenz curves intersect: it is not hard to find cases where the Gini indicates that distribution A is more unequal than distribution $\mathrm{B}$, but that the coefficient of variation indicates the opposite.
} 


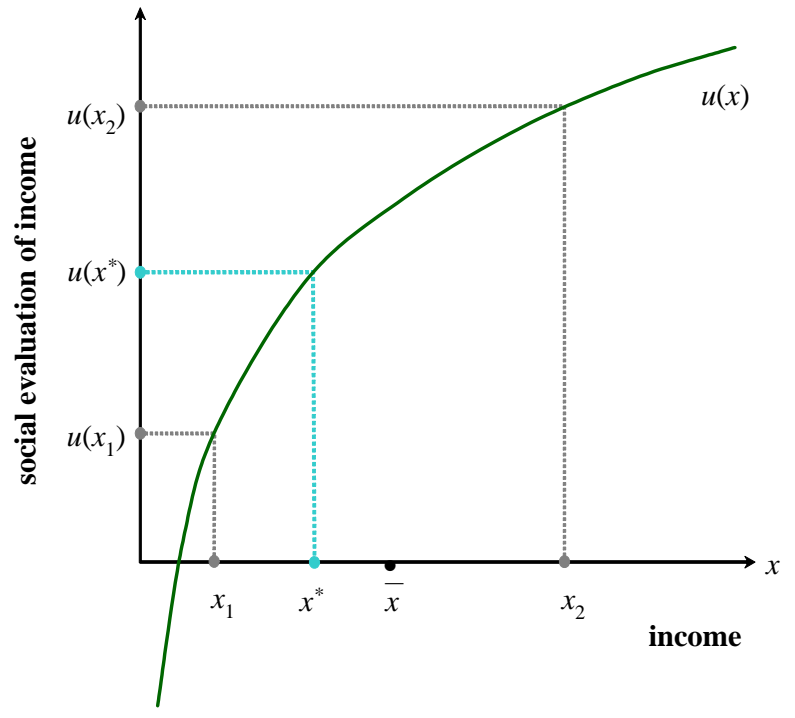

Figure 5: Social evaluation function $u$, equally-distributed-equivalent income $x^{*}$ and mean income $\bar{x}$

where $u$ is a "social-evaluation function" which is increasing (so that more income for person $i$ means higher social welfare) and strictly concave (so that a poorer-to-richer transfer will reduce $W$ - the transfer principle again). An example of this type of function is given in Figure 5. Let us look at two important ways in which this apparatus is used.

Welfare dominance. For the above special type of $W$-function there is a nice relationship with the Lorenz concept. For any distribution construct the Generalised Lorenz Curve (GLC) by multiplying each income share by the mean of the distribution; then if the GLC for distribution $A$ lies somewhere above and nowhere below the GLC for distribution $B$ social welfare must be higher in $A$ than in $B$ for every possible $W$ of the above type (Shorrocks 1983).

Figure 6 draws the GLCs for the US data that we used earlier: it is clear that the two curves intersect, but what does this mean? Both average income and inequality increased over 1987-2003; social welfare increased because of the first effect and decreased because of the second, but neither of the two effects dominates; different $W \mathrm{~s}$, corresponding to different specifications of $u$ in (3) will yield different conclusions as to whether welfare rose (because of the growth in total income) or fell (because of the more unequal shares in total income).

Welfare-based inequality measurement. Find the income level which, if received by everyone, would yield the same level of social welfare. From (3) this 


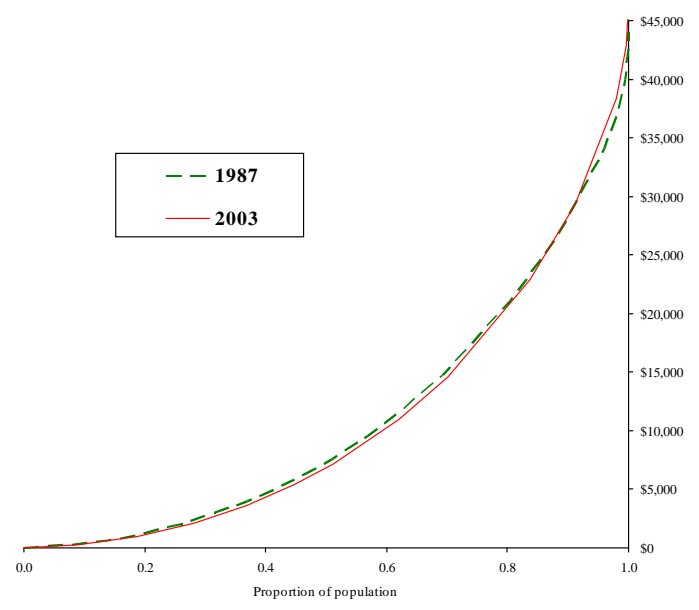

Figure 6: Generalised Lorenz Diagram. US income before tax 1987 and 2003 (in $2003 \$$ )

is a number $x^{*}$ such that

$$
u\left(x^{*}\right)=\frac{1}{n} \sum_{i=1}^{n} u\left(x_{i}\right)
$$

$x^{*}$ is a effectively a dollar measure of social welfare and is illustrated in Figure 5 , for a two-person income distribution $\left(x_{1}, x_{2}\right)$. If $x_{1}$ and $x_{2}$ are moved further apart from each other then clearly the gap between $x^{*}$ and the mean $\bar{x}$ increases; so we could use the proportionate size of this gap, $1-x^{*} / \bar{x}$, as an index of inequality. In the special case where $u(x)$ takes the form $\frac{1}{1-\varepsilon}\left[x^{1-\varepsilon}-1\right]$ this concept yields the class of Atkinson indices (Atkinson 1970):

$$
1-\left[\frac{1}{n} \sum_{i=1}^{n}\left[\frac{x_{i}}{\bar{x}}\right]^{1-\varepsilon}\right]^{\frac{1}{1-\varepsilon}}
$$

The number $\varepsilon$, the degree of relative inequality aversion, is a parameter that characterises individual members of the class of inequality and may take any positive value. ${ }^{11}$ It encapsulates the imputed social values regarding inequality: at the limiting value of zero one is imputing complete indifference to inequality, so that social welfare is measured by mean income $\left(x^{*}=\bar{x}\right)$; as successively higher values of $\varepsilon$ are considered we are imputing a higher premium on inequality and, for any given income distribution, the gap between $x^{*}$ and $\bar{x}$ will increase.

\footnotetext{
${ }^{11}$ The limiting form of $u$ as $\varepsilon \rightarrow 1$ is $\log (x)$ and the limiting form of (5) as $\varepsilon \rightarrow 1$ is $1-\exp \left(\frac{1}{n} \sum_{i=1}^{n} \log \left(x_{i} / \mu\right)\right)$.
} 
To illustrate, suppose we calculate social welfare for the 1987 and 2003 income-distribution data, taking this specific form of the social-evaluation function $u$. We can do this using the equally-distributed equivalent income $x^{*}$ : for successively higher values of inequality-aversion $\varepsilon$ we will get lower values of $x^{*}$ in each of the two years. The results are depicted in Figure 7: for low values of $\varepsilon$ (close to indifference to inequality) welfare is clearly higher in 2003, reflecting the higher mean income in that year; but for higher values of $\varepsilon$ (above about 0.76 , where the curves cross) the premium being put on inequality is so high that welfare is counted as higher in 1987 than in 2003.

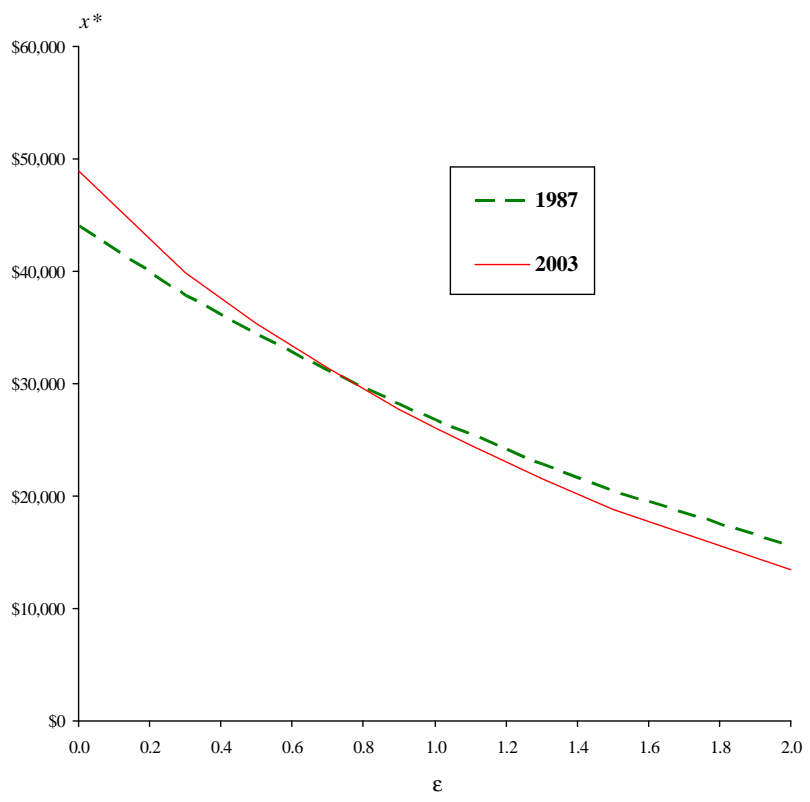

Figure 7: Social welfare for different degrees of inequality aversion. US income before tax 1987 and 2003 (in $2003 \$$ )

\section{$6 \quad$ New directions?}

Two broad channels show considerable promise for the immediate future of research on income distribution and inequality.

Data developments The availability of new, reliable data sources almost inevitably has a stimulating effect on research. The development of micro-data on incomes in developing economies has facilitated not only the analysis of income distribution within each country concerned but the tricky question of 
meaningful international comparisons. It enables one to better address questions such as whether inequality is good for growth (Aghion et al. 1999) and the directions that the world distribution of income is taking (Sala-i-Martin 2006).

However, as Figure 4 shows, significant improvements in data availability are not confined to developing countries. A renewed interest in the fine detail of the income distribution among the seriously rich has led to the synthesis of data from tax authorities that has added a new perspective to international comparisons Piketty (2007); new work making available micro-data on wealth will also enhance understanding of what is going on in the upper tail of the income distribution (Sierminska et al. 2006).

Inequality and the basis for social intervention The idea of inequality has long been associated with public policy prescriptions, addressing questions of whether more resources should be devoted to redistributive programmes, the meaning of tax progression and so on. For the last 35 years or so this literature has largely been based on essentially a welfarist approach to social judgments (Sen 1979). Moreover the particular form of welfarism has typically been rather narrow: the nature of inequality and of inequality aversion has been sought in a kind of social analogy with risk and risk-aversion.

Recent years have seen a reappraisal of this theoretical underpinning. The analysis of preferences under uncertainty and of preferences has been developed to richer models than simple expected-utility and to encompass broader concepts of risk-aversion (Chateauneuf et al. 2004); this is leading to parallel developments in the treatment of the concept of inequality aversion (Chateauneuf and Moyes 2000). Furthermore the growing appreciation of the contribution of "behavioural public economics" (Bernheim and Rangel 2005) has led to a search for an understanding of social-welfare criteria that are not based on simplistic models of individual rationality. Along with this a strong interest has developed in nonwelfarist policy prescriptions that are based on broader criteria of fairness and that show appropriate concern for individual responsibility (Fleurbaey 2008, Kanbur et al. 2006). This reappraisal has influenced thinking about the ethical basis of inequality analysis: Devooght (2007) has examined a responsibility-sensitive approach to income inequality and Cowell and Ebert (2004) have shown how alternative philosophical approaches to welfarism can be encapsulated in inequality measures that are related to concepts of deprivation.

These developments are likely to ensure that concerns with inequality will remain high on the socio-economics research agenda for some time to come.

\section{References}

Acemoglu, D. (2002). Technical change, inequality, and the labor market. Journal of Economic Literature 40, 7-72.

Aghion, P., E. Caroli, and C. Garcia-Penalosa (1999). Inequality and economic growth: The perspectives of the new growth theories. Journal of Economic Literature 37, 1615-60. 
Arrondel, L. and A. Laferrère (2001). Taxation and wealth transmission in France. Journal of Public Economics 79, 3-33.

Atkinson, A. B. (1970). On the measurement of inequality. Journal of Economic Theory 2, 244-263.

Atkinson, A. B. (1997). Bringing income distribution in from the cold. The Economic Journal 107, 297-321.

Atkinson, A. B. and A. Brandolini (2001). Promise and pitfalls in the use of secondary data-sets: Income inequality in oecd countries as a case study. Journal of Economic Literature 39, 771-799.

Bernheim, B. D. and A. Rangel (2005). Behavioral public economics: Welfare and policy analysis with non-standard decision makers. Working Paper 11518, National Bureau of Economic Research, http://www.nber.org/papers/w11518.

Bertola, G. (1993). Factor shares and savings in endogenous growth. The American Economic Review 83, 1184-1198.

Blau, F. D. and L. M. Kahn (1996). International differences in male wage inequality: institutions versus market forces. Journal of Political Economy 104(4), 791-837.

Blundell, R. and I. Preston (1998). Consumption inequality and income uncertainty. The Quarterly Journal of Economics 113, 603-640.

Burtless, G. (1995). International trade and the rise in earinings inequality. Journal of Economic Literature 33(2), 800-816.

Charness, G. and M. Rabin (2002). Understanding social preferences with simple tests. Quarterly Journal of Economics 117, 817-869.

Chateauneuf, A., M. Cohen, and I. Meilijson (2004). Four notions of meanpreserving increase in risk, risk attitudes and applications to the rankdependent expected utility model. Journal of Mathematical Economics 40, $547-571$.

Chateauneuf, A. and P. Moyes (2000). Inequality measurement and theweakening of the transfer principle. Technical report, GRAPE.

Cowell, F. A. (2000). Measurement of inequality. In A. B. Atkinson and F. Bourguignon (Eds.), Handbook of Income Distribution, Chapter 2, pp. 87-166. Amsterdam: North Holland.

Cowell, F. A. (2007). Measuring Inequality (Third ed.). Hemel Hempstead: Oxford University Press.

Cowell, F. A. and U. Ebert (2004). Complaints and inequality. Social Choice and Welfare 23, 71-89.

Cowell, F. A. and M.-P. Victoria-Feser (2007). Robust stochastic dominance: A semi-parametric approach. Journal of Economic Inequality 5, 21-37. 
Cremer, H. and P. Pestieau (2006). Wealth transfer taxation: a survey of the theoretical literature. In L.-A. Gérard-Varet, S.-C. Kolm, and J. MercierYthier (Eds.), Handbook of the Economics of Giving, Reciprocity and Altruism, Volume 1. Amsterdam: North Holland.

Dalton, H. (1920). Measurement of the inequality of incomes. The Economic Journal 30, 348-361.

Devooght, K. (2007). To each the same and to each his own: A proposal to measure responsibility-sensitive income inequality. Economica 74.

DiNardo, J. and J.-S. Pischke (1997). The returns to computer use revisited: Have pencils changed the wage structure too? Quarterly Journal of Economics 112, 291-303.

Fehr, E. and U. Fischbacher (2002). Why social preferences matter - the impact of non-selfish motives on competition, cooperation and incentives. The Economic Journal 112, C1-C33.

Fehr, E. and U. Fischbacher (2003). The nature of human altruism. Nature 425, 785-791.

Fernández, R., N. Guner, and J. Knowles (2005). Love and money: A theoretical and empirical analysis of household sorting and inequality. Quarterly Journal of Economics 120, 273-344.

Ferrer-i-Carbonell, A. (2005). Income and well-being: an empirical analysis of the comparison income effect. Journal of Public Economics 89, 997-1019.

Fleurbaey, M. (2008). Fairness, Responsibility and Welfare. Oxford University Press.

Goldin, C. and L. F. Katz (1996). Technology, skill, and the wage structure: Insights from the past. American Economic Review 86, 252-257.

Gottschalk, P. and T. M. Smeeding (1997). Cross-national comparisons of earnings and income inequality. Journal of Economic Literature 35, 633687.

Gottschalk, P. and T. M. Smeeding (2000). Empirical evidence on income inequality in industrialized countries. In A. B. Atkinson and F. Bourguignon (Eds.), Handbook of Income Distribution, Chapter 3. Amsterdam: North Holland.

Inglehart, R., M. Basáñez, J. Díez-Medrano, L. Halman, and L. Luijkx (Eds.) (2004). Human Beliefs and Values: A Cross-cultural Sourcebook based on the 1999-2002 Values Surveys. Mexico: Siglo Veinteiuno.

Ioannides, Y. M. and L. D. Loury (2004). Job information networks, neighborhood effects, and inequality. Journal of Economic Literature 42, 10561093.

Kaldor, N. (1955). Alternative theories of distribution. The Review of Economic Studies 23, 83-100. 
Kalecki, M. (1939). Essays in the Theory of Economic Fluctuations. London: Allen and Unwin.

Kanbur, R., J. Pirttilä, and M. Tuomala (2006). Non-welfarist optimal taxation and behavioural public economics. Journal of Economic Surveys 20, 849-868.

Kleiber, C. and S. Kotz (2003). Statistical Size Distributions in Economics and Actuarial Sciences. Hoboken. N.J.: John Wiley.

Kopczuk, W. and J. P. Lupton (2007). To leave or not to leave: The distribution of bequest motives. Review of Economic Studies 74, 207-235.

Krueger, A. B. (1993). How computers have changed the wage structure: Evidence from microdata. Quarterly Journal of Economics 108, 33-60.

Krugman, P. and A. J. Venables (1995). Globalization and the inequality of nations. The Quarterly Journal of Economics 110, 857-880.

Liu, H. and J. Lu (2006). Measuring the degree of assortative mating. Economics Letters 92, 317-322.

Lorenz, M. O. (1905). Methods for measuring concentration of wealth. Journal of the American Statistical Association 9, 209-219.

Manning, A. (2003). Monopsony in Motion: Imperfect Competition in Labor Markets. Princeton, N.J.: Princeton University Press.

Manski, C. F. (2000). Economic analysis of social interactions. The Journal of Economic Perspectives 14, 115-136.

Marjit, S. and R. Acharyya (2003). International Trade, Wage Inequality and the Developing Economy: A General Equilibrium Approach. Springer.

Pareto, V. (1965). Écrits sur La Courbe de la Repartition de la Richesse, Volume 3 of Oeuvres Complètes. Geneva: Librairie Droz.

Pasinetti, L. L. (1962). Rate of profit and income distribution in relation to the rate of economic growth. The Review of Economic Studies 29, 267279.

Pen, J. (1974). Income Distribution (second ed.)., Chapter 3, pp. 48-59. London: Allen Lane, The Penguin Press.

Persky, J. (1992). Retrospectives: Pareto's law. The Journal of Economic Perspectives 6(2), 181-192.

Piketty, T. (2000). Theories of persistent inequalities. In A. B. Atkinson and F. Bourguignon (Eds.), Handbook of Income Distribution, Chapter 6, pp. 429-476. Amsterdam: North Holland.

Piketty, T. (2007). Top incomes over the twentieth century: A summary of the main findings. In A. B. Atkinson and T. Piketty (Eds.), Top Incomes Over the Twentieth Century: A Contrast Between Continental European and English-Speaking Countries. Oxford University Press.

Piketty, T. and E. Saez (2003). Income inequality in the United States, 19131998. Quarterly Journal of Economics 118, 1-39. 
Richardson, J. D. (1995). Income inequality and trade: How to think, what to conclude. The Journal of Economic Perspectives 9, 33-55.

Sala-i-Martin, X. (2006). The world distribution of income: Falling poverty and ... convergence, period. Quarterly Journal of Economics 121, 351-397.

Salanié, B. (1997). The Economics of Contracts: A Primer. Cambridge Massachusetts: MIT Press.

Sen, A. K. (1979). Personal utilities and public judgements: or what's wrong with welfare economics? The Economic Journal 89, 537-558.

Sen, A. K. and J. E. Foster (1997). On Economic Inequality (Second ed.). Oxford: Clarendon Press.

Shorrocks, A. F. (1983). Ranking income distributions. Economica 50, 3-17.

Sierminska, E., A. Brandolini, and T. Smeeding (2006). The Luxembourg Wealth Study - a cross-country comparable database for household wealth research. Journal of Economic Inequality 4, 375-383. 